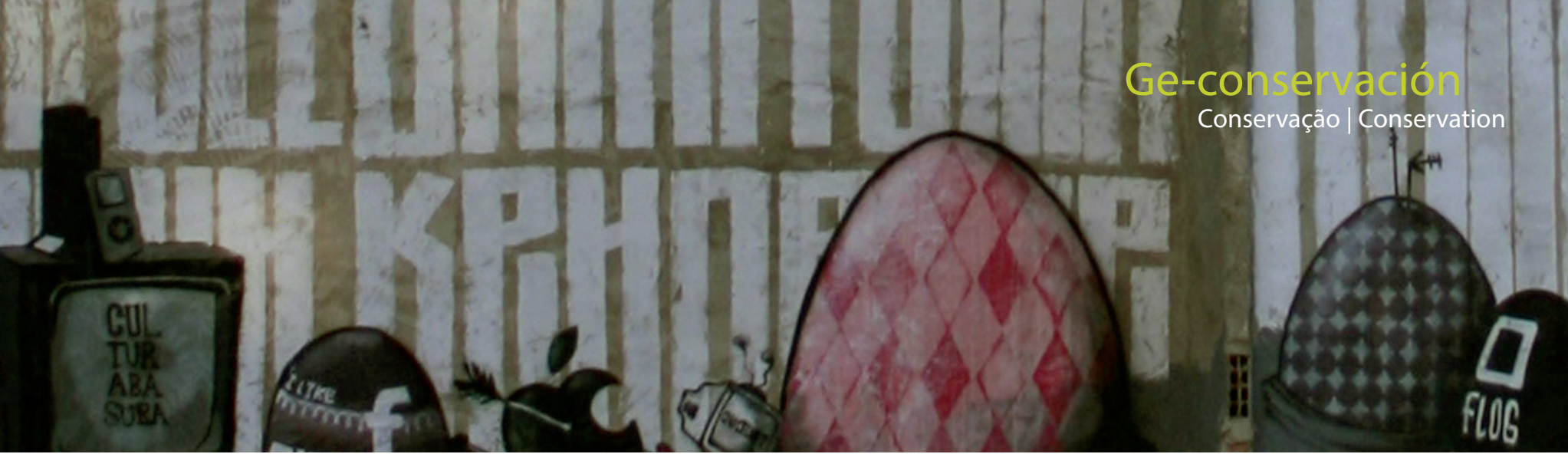

\title{
M.I.A.U. (Fanzara), una propuesta social. Historia, materiales y conservación
}

\author{
Ma Teresa Pastor Valls
}

Resumen: El M.I.A.U., Museo Inacabado de Arte Urbano de Fanzara (Castellón) constituye un proyecto en constante cambio y crecimiento, en el que conviven los murales, la música, la danza, y otras muchas propuestas artísticas. Se trata de un proyecto que surgió como una iniciativa de carácter social con el objetivo de promover la convivencia y la cohesión social a través del arte y la cultura. Una iniciativa que ha superado todas las previsiones, alcanzando una gran repercusión a nivel nacional e internacional, gracias a la cual se ha puesto en el mapa a esta pequeña población.

El carácter social del M.I.A.U. está provocando el debate en torno al carácter efímero de las obras, planteando de este modo la necesidad de su conservación futura. En este sentido, creemos necesario recabar la mayor información posible sobre las técnicas y materiales empleados.

Palabras clave: arte urbano, pintura, conservación, materiales, M.I.A.U., Fanzara, Castellón

\section{M.I.A.U. (Sanzara), a social proposal. History, materials and conservation}

Abstract: The M.I.A.U., Unfinished Museum of Urban Art Fanzara (Castellón) is a project in constant change and growth, in which coexist murals, music, dance, and many other artistic proposals. This is a project that began as an initiative of a social character with the aim of promoting coexistence and social cohesion through art and culture. An initiative that has exceeded all expectations, reaching a major impact at national and international level, thanks to which the small town of Fanzara has been put on the map.

The social character of M.I.A.U, is causing a debate regarding the ephemeral nature of the works, thus raising the need for future conservation. In this sense, we need to gather as much information as possible about the techniques and materials used.

Key words: Street Art, paint, conservation, materials, M.I.A.U., Fanzara, Castellón

\section{EI M.I.A.U. (Fanzara), Museo Inacabado de Arte Urbano}

Recién cumplida su tercera edición, el M.I.A.U., Museo Inacabado de Arte Urbano de Fanzara (Castellón), es un proyecto social que se planteó en un momento muy complicado para la población con el objetivo de fomentar la convivencia, el diálogo y el sentimiento de unidad, a través del arte y la cultura. Para ello, Javier López y Rafa Gascó, idearon un proyecto de todos y para todos, capaz de promover además la convivencia intergeneracional entre vecinos y artistas.

Esta propuesta, se celebra en el mes de julio en el municipio castellonense de Fanzara. Un pequeño y tranquilo pueblo del Alto Mijares de poco más de 300 habitantes, bañado por las aguas del río que da nombre a esta comarca y rodeado de bosques de pinos y encinas, que se localiza a unos 35 kilómetros de la capital de provincia.

Como museo inacabado, el M.I.A.U., se encuentra en constante cambio y crecimiento, en el que su filosofía sociocultural promueve la coexistencia de diversas propuestas artísticas como la realización de murales, la música, la danza, la proyección de películas, la realización de ciclos de conferencias y talleres, en la que no faltan las visitas guiadas y la participación ciudadana de todas las edades. (M.I.A.U. 2016, Bosch 2015). [Figura 1]. 

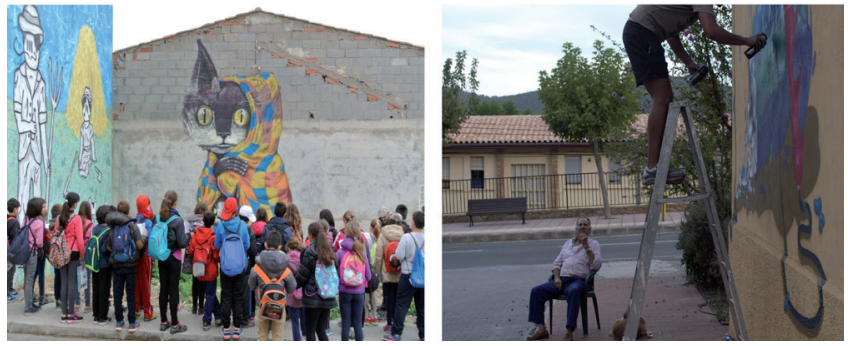

Figura 1. Grupo de alumnos/as del CEIP Pinar Grao de Castellón frente al mural de Bibbito y Thiago Goms. Vecino y perro a la fresca mientras se pinta mural. Fotos: M.I.A.U (1a) y Rafa Gascó.

Se trata de un museo situado en las calles del pueblo, gratuito y de libre acceso, organizado por amor al arte y sin contraprestaciones. La asociación M.I.A.U. y el Colectivo G.U.A.U. (Gestores Universales de Arte Urbano) son fundamentales en este sentido, así como la difusión online a través de su web, Facebook o Twitter, en la que se comparten noticias, imágenes, y en la que es posible adquirir productos través de la tienda online o la descarga del plano y programación. Materializado gracias al esfuerzo y a la ilusión, y bajo el lema Tomar y hacer, en lugar de pedir y esperar, cuenta con recursos económicos muy limitados, así como con la participación de diversas instituciones y empresas ${ }^{1}$.

Abiertos a la colaboración e implicados en diversas iniciativas socioculturales, se mantienen en contacto con artistas, críticos, así como con otros certámenes, siendo numerosos los medios nacionales e internacionales de prestigio que se han hecho eco de este proyecto. Pues, la repercusión que dicha iniciativa está teniendo para este pequeño pueblo del Alto Mijares ha superado todas las expectativas planteadas inicialmente. En reconocimiento de su labor, acaban de recibir los Premios Arte Blanco Pilares de la Cultura Provincia de Castellón 2016 IV edición (M.I.A.U. 2016).

Si nos centramos en las diferentes manifestaciones artísticas, cabe señalar que fueron concebidas a priori como efímeras, en las que su pervivencia o contemplación se encuentra relacionada con la necesidad de nuevos espacios sobre los que crear o en función de su propio estado de
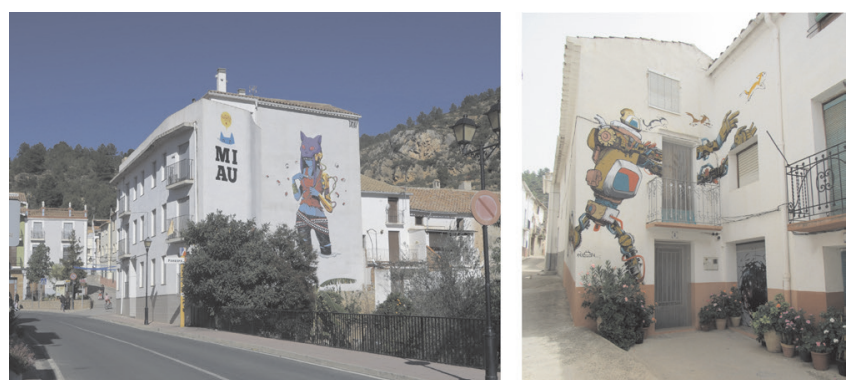

Figura 2. Logo del M.I.A.Uy mural de DEIH a la entrada de Fanzara. Foto: Rafa Gascó. Obra de Xèlön adaptándose a la estructura de una vivienda. Foto: Mayte Pastor. conservación. No obstante, el carácter social del M.I.A.U. está provocando que la propia comunidad interiorice algunas obras dotándolas de unos valores propios que las convierten en representativas, lo cual está llegando a plantear la necesidad de su conservación futura. En este sentido, creemos necesario recabar la mayor información posible sobre las técnicas y materiales empleados.

\section{Selección de artistas y obras}

Tras tres años de búsqueda, espera y esfuerzo, aquel sueño del M.I.A.U. se hizo realidad en el verano de 2014 gracias al ayuntamiento y al inestimable apoyo del artista Miguel Abellán "Pincho", quien pronto implicó a otros artistas urbanos en este proyecto social. Su visita, junto a la de Sabek y Ruina, junto al contacto con la asociación Murmurs fueron decisivas en este sentido. $Y$ por supuesto, la implicación de vecinos y artistas, que hoy forman una gran familia. Así, sin casi creerlo, en aquella primera edición del M.I.A.U. se contó con la participación de veintiún artistas que realizaron cuarenta y cuatro intervenciones ${ }^{2}$. El logo de Pincho y la gata de DEIH, hijo predilecto de Fanzara, nos reciben a la entrada del pueblo [Figura 2a].

En la segunda edición, se pidió a los 21 artistas participantes del año anterior que propusieran a otros artistas que encajaran en el proyecto, realizando una selección. En la edición del corriente año 2016, la participación ha venido dada por un sistema de selección doble. Por una parte se ha contado con las propuestas de los artistas participantes en años anteriores y por otro, se ha realizado una convocatoria de participación abierta a nuevos creadores. Tal y como nos indican desde la organización, al tratarse de un museo, se busca la calidad y variedad, incluyendo nuevas propuestas que completen la colección artística urbana del M.I.A.U. Además de la ejecución de murales se ha contado con diversas intervenciones artísticas realizadas con materiales de reciclaje y basura, etc.

La siguiente tabla corresponde a los requisitos que se solicitaron a todos los artistas interesados en participar en el proyecto del M.I.A.U. 2016 y que transcribimos literalmente en el presente artículo (M.I.A.U. 2016). Como podemos observar, los valores de convivencia e intercambio a través del uso social del espacio quedan plasmados en esta propuesta [Tabla 1].

Al tomar como fuente los mapas y programas difundidos por la organización, se constata un crecimiento exponencial de las propuestas en solo tres años. En la actualidad el M.I.A.U. cuenta con la representación de artistas de talla nacional e internacional: Acció Poètica La Plana, Ana Pez, Animalito Land, Bibbito, Borondo, BTOY, Cere, Chylo, Col.lectiu Paral.lel, Collettivo FX, Costi, DEIH, Dingoperromundo, Escif, Emilio Cerezo, Gael, GR170, Hombre López, Hyuro, H101, Ilia Mayer, Isaac Mahow, Joan Tarragó, Joaquín Jara, Julieta XLF, Julián Arranz, Kenor, Laguna, Lolo, Luis Montolio, Martin Firrell, Natxuta, 
Que se adapten al medio, que sean majos y que sepan dibujar (por este orden).

Los artistas del Festival 2015 proponen dos nombres.

Todos los demás que queráis participar podéis enviar vuestro proyecto, ideas,... a miau.fanzara2014@gmail.com

Entre todas las propuestas recibidas la Asociación MIAU y el colectivo GUAU seleccionarán los artistas que participaran en el festival 2016.

(Si no sois seleccionados no desesperéis, el presupuesto es corto, pero habrá más ediciones) Asociación MIAU.

Tabla 1. Requisitos de los participantes M.I.A.U. edición 2016 (M.I.A.U. 2016).

NemO's, PichiAvo, Pincho, Pol Marban, Rodrigo Branco, Rosh Trestrestres, Ruina, Sabek, Srger, Susie Hammer, Taltos, Thiago Goms, Xavier XTRM, Xèlön y Yes.

Aparte se ha contado con otras propuestas tales como talleres y exposiciones de la mano de artistas como Aïda Gómez, Arquicostura, Artinwreck, Basurama, Bubble, Juan Plasencia (Fila 7), Luis Montolio (Fotografia XXL), Maya Jankovic (La Fontana della Fortuna), Trashformaciones, Secret Boards, etc., así como proyecciones de cine o actuaciones musicales: Lydia López, Daniel Chiva, The Small Street Band, DJ Gabho, DJ Casius Tonen, Rondalla Santa Cecilia de Fanzara (ronda a los artistas).

¿Pero cómo se eligen los lugares para ejecutar las distintas manifestaciones artísticas? Según Javier López, uno de los organizadores del M.I.A.U., son los propios vecinos los que ceden las paredes para pintar, animándose unos a otros ${ }^{3}$. Una vez tienen localizadas las superficies disponibles, realizan una fotografía con alguien sujetando un metro abierto delante de la pared. De este modo, pueden remitirlas a los artistas para que elijan el mejor lugar para ejecutar sus respectivos proyectos. Señala también que son muy pocos los que realizan un boceto, pues son conscientes de que los diseños pueden cambiar al llegar al pueblo, convivir e impregnarse de la esencia de sus calles y del carácter de sus gentes. Pues, es esa precisamente la filosofía del M.I.A.U., y para ponerla en práctica los artistas comienzan la ejecución de las obras tres días después de su llegada al pueblo, sin que los propietarios sepan qué van a pintar sobre sus viviendas.

Así lo pone de manifiesto en su blog la crítica Irene Gras Cruz tras su llegada a Fanzara:

“...NemO's estaba meditando frente la pared que iba a intervenir. Es como si mantuviese un diálogo con ella. Los tres artistas se debaten sobre qué plasmar en Fanzara y tras estudiar y escuchar a la gente del pueblo, Bibbito se decanta por representar 'La era' puesto que la pared que escoge está en la calle de 'Las Eras' mientras que Collettivo FX decide pintar la mano del hombre que le deja el muro, la mano de un hombre trabajador, labrador y que representa la dureza y el esfuerzo de toda una vida al servicio del campo. Del mismo modo, NemO's escoge un tema más comprometido y controvertido con la zona" (Gras 2015)
No hay censura ni prohibiciones, pero sí se pide que se tenga en cuenta que en el pueblo hay gente muy mayor. Debe prevalecer el espíritu de convivencia, las ganas de compartir y disfrutar, como las de escuchar a los vecinos y vecinas cada vez que interrumpen a los artistas para preguntar, curiosear o aprender. "No es solamente ir a pintar..., es algo social" -señala López -"No puede venir cualquiera..., ha de ser un buen/a tío/a, que se adapte al medio y que pinte perfecto". Y así, es como salen las ideas, las propuestas, incluso las colaboraciones entre artistas. No olvidemos que son los vecinos y vecinas los que acogen a gastos pagados a los artistas durante cuatro días, en un ambiente lleno de cultura y fiesta, en el que se fraguan amistades y emergen ideas ${ }^{4}$.

\section{Técnicas y materiales}

Llegados a este punto, nos centraremos en las técnicas y materiales empleados por los artistas participantes en el M.I.A.U., un tema de gran importancia y de gran implicación tanto para comprender este tipo de manifestación artística como para su posible conservación. De este modo, podemos agruparlos en soportes, fondos y capas de color (materiales pictóricos y no pictóricos).

Las paredes que sirven de soporte a los murales u otro tipo de intervenciones son de todo tipo y presentan distinto estado de conservación. De las de piedra tradicional con restos de mortero de cal y capas de pintura (a la cal y/o sintéticas), pasamos a las de ladrillo o a los bloques de cemento, así como a los muros cubiertos de cemento Portland $^{\circledR}$, los cuales pueden estar o no recubiertos con pintura de exteriores y presentar toda clase de acabados con superficies lisas a rugosas.

Según lo expuesto, fachadas de viviendas, garajes, corrales, edificios públicos, muros o el asfaltado de un aparcamiento, pueden albergar obras de gran calidad. Y no solamente los muros, las puertas (de madera o metálicas), las tapas de los registros de los contadores del agua (acero o aluminio), las señales de tráfico o los contenedores de plástico verde del vidrio reciclado son elegidos como soportes ${ }^{5}$.

Al respecto, la artista Ana Pez afirma que en la ejecución de su bosque en una de las estrechas calles del pueblo, empleó la gama cromática del entorno. “...e integré una 

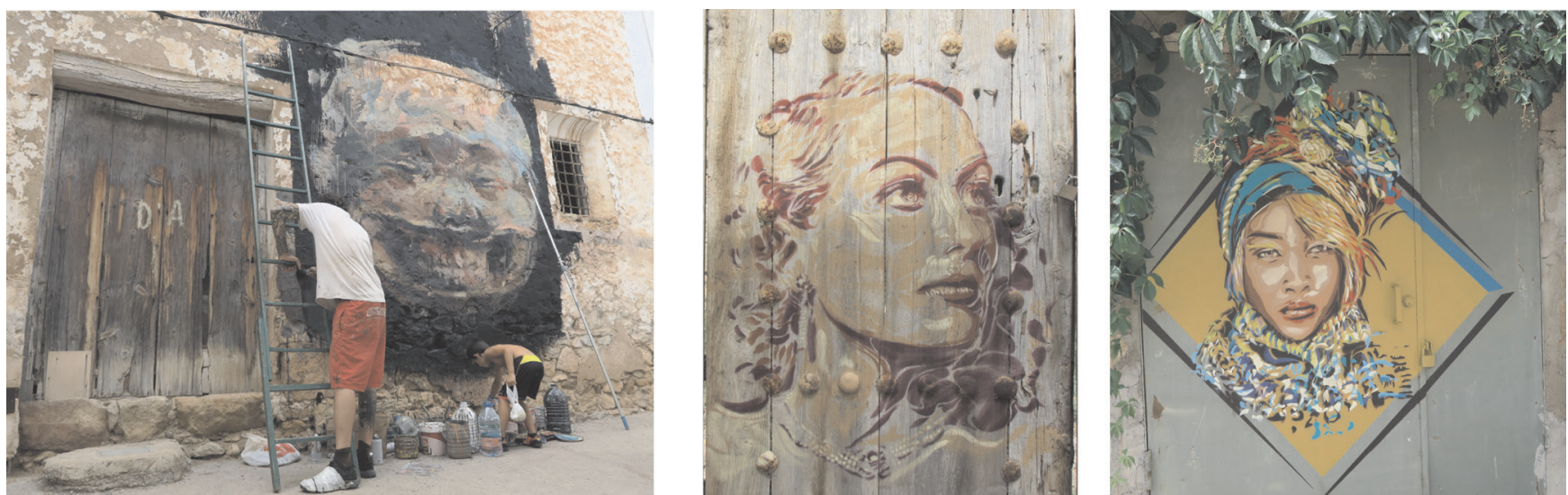

Figura3. Cerezo pintando sobre una casa de piedra y detalles pinturas de BTOY sobre puerta de madera y metal. Fotos: Rafa Gascó (3a y 3c) y Mayte Pastor (3b).

puerta para construir el árbol principal, cuyas ramas (con la ayuda de Julián Arranz, quien cortó, pintó y colocó las maderas) crecieron hasta salirse de la pared...." (Pez 2014).

Dichos soportes tienen una trascendencia directa en las obras tanto a nivel creativo como por lo que respecta a una posible futura conservación. Ya que estos transmiten ciertas cualidades y características al acabado, inspirando el diseño o incluso formando parte de él, aportando texturas, tonalidades y formas. Así encontramos pinturas que cubren total o parcialmente los paramentos, junto a otras obras que se sirven de los desconchados de la pared o de los remiendos de cemento de los muros, incorporándolos como elementos creativos. [Figura 3]

En la calle Purísima, BTOY plasmó un retrato femenino sobre una puerta de madera, material que aporta calidez y una influencia directa sobre la obra dándole el aire vintage de las divas del cine clásico. La misma artista pinta sobre una puerta metálica con esmalte y el resultado es diferente, quizá más pop [Figura 3b y 3c]. Por supuesto, son cuestiones que definirán correctamente los historiadores y críticos del arte, si bien, desde nuestro punto de vista sí podemos observar la influencia de la selección de los materiales sobre las obras. Otro caso similar es el de Emilio Cerezo, quién trabaja de forma consciente sobre paredes viejas con distintos niveles de degradación [Figura 3a].

Al igual que el anterior, otros autores como Susie Hamer, Hyuro, Lolo, Sabek e Isaac Mahow pintan sobre las grises fachadas, dejando partes a vistas y sirviéndose de esta tonalidad para resaltar la composición. Estos pueden ser bloques de hormigón o enlucidos de origen. Thiago Goms, aprovecha este recurso en la parte superior del muro al pintar a sus gatos, combinando con restos de pintura en la primera mitad. Así mismo, NemO's pinta la balanza sobre el gris cemento, encajando el diseño entre el revestimiento y los bloques de la mediana.

La historia oral, los dichos y canciones, también tienen su representación en este museo a cielo abierto. En las tapas de los registros del agua, encontramos los "Registros del habla" de Hombre López, al que se sumó la participación vecinal. Dejando a vistas parte de la superficie metálica, unos personajes esquemáticos muestran en esmalte color turquesa oscuro, negro y blanco, las frases típicas del hablar de esta zona de transición lingüística entre valenciano y el castellano de Teruel [Figura 5].

Según el estado de las superficies, en ocasiones es necesario aplicar alguna capa de imprimación, pero suele recurrirse a bases de pintura de color blanco o negro, dando paso a los materiales del estrato de color propiamente dicho. Alejados de las preparaciones tradicionales, estos materiales o fondos, acostumbran a ser pictóricos, incluyendo los recubrimientos, esmaltes y barnices de fachadas, a los que se suman superficies como puertas y otros elementos. Ya hemos comentado que los paramentos suelen prepararse con bases blancas, pero esto no siempre es así, pues el artista puede encontrar en los propios muros materiales con características y desiguales estados de conservación que inspiran o sustentan las propias creaciones, pasando a formar parte de ellas ${ }^{6}$.

Por ejemplo, DEIH pinta The Visitor sobre un fondo blanco, al igual que Animalito Land o PichiAvo. Escif, Xèlön o Cere aprovechan en la composición el color con el que están ya pintadas las fachadas (ocre, blanco). El Colectivo FX emplea un fondo de color blanco para su diseño, pero este está enmarcado por el gris del muro.

Los materiales pictóricos son adquiridos por la organización del M.I.A.U., según demandan los artistas en base a la idea o el boceto presentando, tal y como relata con gran detalle Javier López. De forma habitual se utilizan pinturas en spray específicas para grafiti de la marca catalana Montana Colors S.L. (MTN ${ }^{\circledR}$ ) y pintura plástica de la empresa castellonense Pinturas Colom ${ }^{\circledast}$ (Hijo de Guillermo Colom S.A.), ambas colaboradoras del M.I.A.U. No obstante se atienden de forma expresa las peticiones y preferencias de los artistas, que pueden solicitar tintas, rotuladores, fijadores $\mathrm{u}$ otros materiales ${ }^{7}$. Rodillos, brochas, aerosoles, tampones de estampar o plantillas son algunos de los sistemas de aplicación de estas pinturas [Figura 4]. 

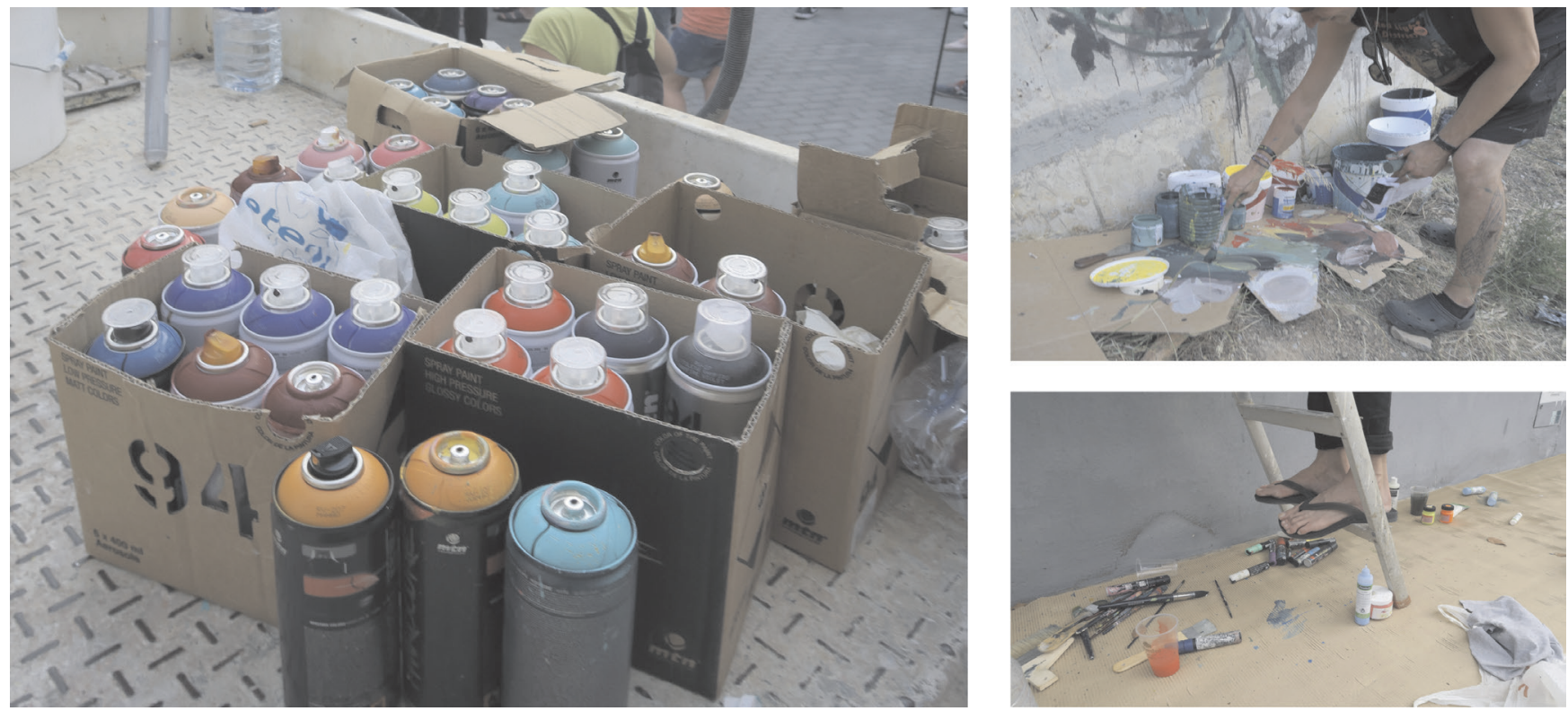

Figura4. Materiales pictóricos. Fotos: Rafa Gascó.

En las tablas siguientes se muestra la línea de pinturas seleccionadas, tal y como nos especifica López. Pinturas Colom $^{\circledR}$ suministra la pintura plástica en los tonos básicos blanco y negro, junto a diversos colores (magenta, amarillo, bermellón, azul ultramar) para su posterior mezcla por los artistas [Tabla 2]. La línea Mayen Color ${ }^{\circledR}$ se fabrica para el revestimiento de interiores y exteriores con resinas acrílicas de alta calidad y pigmentos de gran estabilidad, ofreciendo un alto grado de lavabilidad, rendimiento y cubrición. Producidas con emulsiones acuosas de resinas estireno-acrílicas son las pinturas de interior Tinmate ${ }^{\circledR}$, que combinadas con los Tintes Lys ${ }^{\circledR}$ (bases pigmentarias de alta calidad) son mezcladas para obtener las distintas tonalidades necesarias (Pinturas Colom 2016).

A su vez, se emplean pinturas en spray fabricadas de forma específica para el mundo del grafiti por la marca $\mathrm{MTN}^{\circledR}$, con resinas alquídicas modificadas en mezclas aromáticas de solventes (ligante cetónico en colores metalizados). La línea MTN $94^{\circledR}$ proporciona acabados mates y la Hardcore ${ }^{\circledR}$ brillantes. Ambas ofrecen una altísima calidad con colores sólidos y gran resistencia tras la polimerización [Tabla 3] e información sobre su opacidad y resistencia a los rayos ultravioletas (Montana Colors 2016).

Otro tipo de medios pictóricos son las acuarelas de las marcas Winsor \& Newton ${ }^{\circledR}$ y Schmincke $^{\circledR}$ que Ilia Mayer combina con rotuladores $\mathrm{UNI}^{\circledR}$ o Pentel ${ }^{\circledR}$ de tinta china como medio de obtener un personal acabado con líneas de dibujo, colores diluidos y transparencias [Figura $4 \mathrm{c}]^{8}$.

Tras la visita a este museo descubrimos obras en blanco y negro (Collectivo FX, Joaquín Jara), con predominio del blanco y línea negra combinadas con color (Pincho), de colores vivos (Juan Tarragó, Bibbito, Animalito Land,
Julieta XLF, Kenor, H101, Srger, Taltos, Thiago Goms, los robots de Xèlön, Rosh 333, etc.), o más apagados, difuminados y sutiles (NemO's), pasteles (rosa, gris y azul en el Family Portrait de GR170), junto a acabados mates, satinados y brillantes, lisos o rugosos. Obras que cubren todo el paramento (Laguna y Xavier XTREM, Bibbito, Srger), o dejan partes al aire. Obras que precisan de la perspectiva para ser contempladas, o de lo contrario, siendo necesaria la proximidad en un espacio de zonas abiertas y callejuelas. Hay murales bajo puentes que hay que atravesar o intervenciones envolventes como la "capilla" de Jara, en la que utiliza tonos de blanco, negro y gris sobre ladrillo rojizo y puerta metálica.

Pero, no todo es pintura. En este sentido, y comprobando una vez más lo importante que es la población felina para este museo, destaca la cara de gato de losetas cerámicas hexagonales de tonos grises de Julián Arranz.

Cualquier material es válido: alimentos, piedras, sillas, cordeles, listones, tornillos, cemento blanco o escayola coloreada (salvavidas para el "Capitalismo" o "dentaduradonuts"), las tapas de los contadores, etc. Pues, en esta categorización de "estratos de color" se incluyen también aquellos materiales que aportan características en este sentido, como las ya citadas tapas metálicas de los registros del agua o la obra sobre madera de BTOY. Material empleado por Artinwreck o en las sillas con o sin asiento obradas en la fachada de una casa (Compañía de Mario). Del mismo modo, las obras "Flor de nocturna" y "Piedra Angular" de Xavier XTREM añaden listones y piezas de madera, junto a cordeles blancos atornillados para dibujar la geometría, dando volumen y profundidad [Figura 5].

Son muchos los ejemplos y la variedad matérica... La planta carnívora de Cerezo que cubre una tubería que la atraviesa, los cables de la luz incorporados a 


\begin{tabular}{|c|c|c|c|c|}
\hline & Línea & Características & MLAU & Composición \\
\hline$\frac{8}{8}$ & $\begin{array}{c}\text { MAYEN } \\
\text { COLOR } \\
\text { (Pintura } \\
\text { para } \\
\text { fachadas) }\end{array}$ & $\begin{array}{l}\text { - Revestimiento de interiores y exteriores, alto } \\
\text { rendimiento y cubrición. } \\
\text { - Disponible en blanco y } 17 \text { colores. } \\
\text { - Impermeable al agua y a la lluvia. Permeable al vapor } \\
\text { de agua. } \\
\text { - Apto para todo tipo de superficies. } \\
\text { - Impermeable, transpirable, alta adherencia, gran } \\
\text { flexibilidad, resistente a la intemperie, lavable, } \\
\text { excelente resistencia a la abrasión. Sobre hormigón } \\
\text { sin defectos proporcionan una excelente protección } \\
\text { contra la carbonatación. } \\
\text { - Las superficies deben estar limpias, exentas de polvo, } \\
\text { manchas de aceite, grasa, etc. } \\
\text { - Instrucciones de uso para superficies lisas o rugosas } \\
\text { (mayor o menor dilución). Ver fichas. } \\
\text { - Aplicación: pistola, brocha o rodillo. } \\
\text { - Rendimiento según rugosidad y absorción de las } \\
\text { superficies: Liso ( } 3 \text { - } 4 \text { m }{ }^{2} / \text { Litro a dos manos); } \\
\text { rugoso ( } 1,5 \mathrm{~m} / \text { Litro a dos manos. } \\
\text { - Secado: Liso ( } 1 \text { h al tacto, } 6 \text { h para el repintado, } 24 \mathrm{~h} \\
\text { secado total); Rugoso ( } 1 \text { h al tacto, } 24 \text { h secado total). } \\
\text { - Lavabilidad (Norma ASTM D - } 2486 \text { d): resistencia } \\
\text { superior a las } 20000 \text { dobles pasadas. } \\
\text { - Aplicar sobre superficies libres de grasa, polvo hollín } \\
\text { o cualquier otro contaminante. } \\
\text { - No almacenar ni aplicar a temperaturas }<5{ }^{\circ} \mathrm{C} \text {. } \\
\text { - Envases de } 750 \text { ml, } 5 \mathrm{Kg}, 15 \text { l. }\end{array}$ & $\begin{array}{l}\text { - Blanco } \\
\text { Mayen } \\
\text { color liso } \\
205 . \\
\text { - Negro } \\
\text { Mayen } \\
\text { color liso } \\
495 .\end{array}$ & $\begin{array}{l}\text { - Revestimiento. } \\
\text { - Resinas } \\
\text { acrílicas alta } \\
\text { calidad. } \\
\text { - Pigmentos } \\
\text { totalmente } \\
\text { sólidos a la luz } \\
\text { y a la } \\
\text { alcalinidad de } \\
\text { las superficies } \\
\text { de cemento y } \\
\text { concretos. }\end{array}$ \\
\hline & $\begin{array}{l}\text { TINMATE } \\
\text { (pintura } \\
\text { mate y } \\
\text { decorativa) }\end{array}$ & $\begin{array}{l}\text { - Gama } 28 \text { colores mates. } \\
\text { - Uso de interiores. } \\
\text { - Colores intensos de pintura de alta cubrición y } \\
\text { lavabilidad. } \\
\text { - Aplicación directa o para teñir pintura blancas. } \\
\text { - Variable solidez a la luz según pigmentos. Estabilidad } \\
\text { en interiores. } \\
\text { - Viscosidad: } 175 \pm 50 \mathrm{P} \text { (brookfield, } 20 \mathrm{rpm} \text { ) } \\
\text { - Peso específico: } 1.2 \text { a } 1.7 \mathrm{gr} . / \mathrm{cc} \text { según color. } \\
\text { - Rendimiento: } 12-14 \mathrm{~m} 2 / \mathrm{Kg} \text {. } \\
\text { - Lavabilidad superior a } 20.000 \mathrm{PSD} \text {. } \\
\text { - Secado: } 20 \text { a } 30 \mathrm{~min} \\
\text { - Repintado: a las } 3 \mathrm{horas} \text {. } \\
\text { - Envases de } 750 \mathrm{ml}, 5 \mathrm{Kg}, 15 \mathrm{l} \text {. }\end{array}$ & $\begin{array}{l}\text { - Bermellón } \\
\text { Tinmate. } \\
\text { - Azul } \\
\text { ultramar } \\
\text { Tinmate. } \\
\text { - Amarillo } \\
\text { 67-acrílico. } \\
\text { - Magenta } \\
\text { 78-acrílico. }\end{array}$ & $\begin{array}{l}\text { - Al agua. } \\
\text { - Resina } \\
\text { estireno- } \\
\text { acrílica, } \\
\text { pigmentos } \\
\text { orgánicos e } \\
\text { inorgánicos } \\
\text { sin plomo, } \\
\text { conservante, } \\
\text { antiespumante } \\
\text { y aditivos. }\end{array}$ \\
\hline & $\begin{array}{c}\text { TINTES } \\
\text { LYS® AL } \\
\text { AGUA } \\
\text { (tintes } \\
\text { concentrados } \\
\text { para teñir } \\
\text { pinturas al } \\
\text { agua) }\end{array}$ & $\begin{array}{l}\text { - Gran poder de tinción. } \\
\text { - Tintes concentrados. Tinción de todo tipo de pinturas } \\
\text { al agua (plásticos, temples, colas, rugosos, cal, etc.). } \\
\text { - Añadir el colorante poco a poco. Se incorporan } \\
\text { - fácilmente por agitación. } \\
\text { - Colores son mezclables entre sí. } \\
\text { - Mantener el envase original bien cerrado. } \\
\text { - } 12 \text { colores según carta. } \\
\text { - Envases: } 60 \mathrm{ml}, 125 \mathrm{ml}, 250 \mathrm{ml} \mathrm{y} 1000 \mathrm{ml}\end{array}$ & $\begin{array}{l}\text { - TL9-tinte } \\
\text { Lys azul. } \\
\text { - TL6-tinte } \\
\text { Lys rojo. }\end{array}$ & $\begin{array}{l}\text { - Pastas } \\
\text { pigmentarias al } \\
\text { agua a base de } \\
\text { pigmentos de } \\
\text { alta calidad }\end{array}$ \\
\hline
\end{tabular}

Tabla 2. Productos Pinturas Colom ${ }^{\circledast}$ (Pinturas Colom 2016). 


\begin{tabular}{|c|c|c|c|c|c|}
\hline Marca & Línea & Tipo & Características & $\begin{array}{l}\text { Aglutinante } \\
\text { /pigmentos }\end{array}$ & Solventes \\
\hline \multirow{2}{*}{ 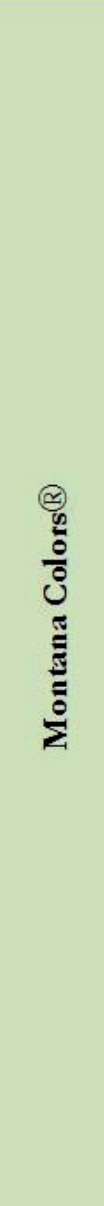 } & 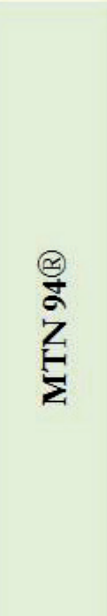 & के & $\begin{array}{l}\text { - Baja presión. } \\
\text { - Mate. } \\
\text { - } 400 \text { ml. } \\
\text { - Colores sólidos: } 174 \text { tonos. } \\
\text { - Buen poder de cubrición. } \\
\text { - Secado rápido. } \\
\text { - Buen endurecimiento. } \\
\text { - Flexibilidad excelente. } \\
\text { - Gran resistencia al rayado tras polimerización. } \\
\text { - No contiene plomo ni metales pesados. } \\
\text { - Durabilidad del color. } \\
\text { - Facilidad de aplicación y repintado. } \\
\text { - Buen comportamiento en la intemperie. } \\
\text { - Muy buena resistencia a los rayos U.V. }\end{array}$ & $\begin{array}{l}\text { Resina } \\
\text { alquídica } \\
\text { modificada }\end{array}$ & $\begin{array}{l}\text { Mezcla aromática: } \\
\text { acetato de etilo, } \\
\text { butano, xileno } \\
\text { (mezcla de } \\
\text { isómeros), } \\
\text { propano, } \\
\text { isobutano, acetato } \\
\text { de 1-metil-2- } \\
\text { metoxietilo, } \\
\text { etilbenceno, } \\
\text { hidrocarburos } \\
\text { C10-C13 alifáticos } \\
\text { (aromáticos <2\%), } \\
\text { 2-butanona-oxima }\end{array}$ \\
\hline & 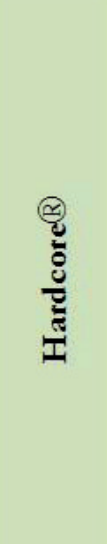 & ते & $\begin{array}{l}\text { - Alta presión. } \\
\text { - Brillo. } \\
\text { - Secado muy rápido. } \\
\text { - Buen endurecimiento. } \\
\text { - Flexibilidad excelente. } \\
\text { - Gran resistencia al rayado tras polimerización. } \\
\text { - No contiene plomo ni metales pesados. } \\
\text { - Buen poder de cubrición. } \\
\text { - Durabilidad del color. } \\
\text { - Facilidad de aplicación y repintado. } \\
\text { - Muy buen comportamiento en la intemperie. } \\
\text { - Muy buena resistencia a los rayos U.V. } \\
\text { (consultar carta) }\end{array}$ & $\begin{array}{c}\text { Resina } \\
\text { alquídicas y } \\
\text { pigmentos de } \\
\text { alta calidad } \\
\text { *Ligante } \\
\text { cetónico: } \\
\text { gama } \\
\text { metalizada }\end{array}$ & $\begin{array}{l}\text { Acetato de etilo, } \\
\text { butano, xilenos, } \\
\text { propano, } \\
\text { isobutano, } \\
\text { etilbenceno, } \\
\text { acetato de 1-metil- } \\
\text { 2-metoxietilo, } \\
\text { hidrocarburos } \\
\text { C10-C13, } \\
\text { isoalcanos, cíclicos } \\
\text { (aromáticos <2\%), } \\
\text { 2-butanona- } \\
\text { oxima. }\end{array}$ \\
\hline
\end{tabular}

Tabla 3. Productos Montana Colors ${ }^{\circledR}$ (Montana Colors 2016).

la composición de rostros de Borondo [Figura 6a], las carrocerías prensadas aparcadas en vertical sobre un muro de Trashformaciones o los bordados a punto de cruz con hilos gruesos de colores sobre rejilla metálica de Arquicostura. [Figura 6]

La técnica de la transferencia fotográfica sobre cantos rodados puede apreciarse en "Redes Sociales" de Hombre López y Rafa Gascó, creando una red de rostros de personas que vivieron y viven en Fanzara [Figura 5b]. A su vez, Bibbito interviene el reverso de una señal de tráfico de la Calle Santo Sepulcro utilizando la técnica del Stickerart.

Mención aparte son aquellas obras que cuentan con materiales orgánicos más o menos perecederos, tales como la guirnalda floral de Borondo en la que combina pintura con cañas [Figura 6b], las formas circulares que encontramos colgadas en las calles o interior del lavadero realizadas con este material y hojas de pino (pintadas o no) por Col.lectiu Paral.lel y vecinas, o los limones y rollos de pan de la intervención artística de Jara (balcón de la Plaza de la Virgen).

\section{Plazos de lo efímero}

El M.I.A.U. es un proyecto social, inacabado, que tiene la vocación de ampliarse y renovarse edición tras edición. Es por ello, que a priori, y en relación a la filosofía del arte urbano, las obras han de entenderse como obras efímeras. Por tanto, los muros se cubrirían con una nueva obra si no hay espacio suficiente o si la degradación de las obras sustenta esta decisión.

En cuanto esta última variable, ¿es posible establecer unos plazos a lo efímero? Cada obra tendrá una evolución particular a nivel de conservación dependiendo de una serie de factores interrelacionados. Esto es, del estado de conservación de los soportes, de la calidad de los materiales y la técnica empleada o de lo resguardadas que estén del impacto de los agentes ambientales (rayos ultravioleta, oscilaciones termohigrométricas, exposición al viento o lluvia, contaminación, etc.) y demás agentes externos.

La aplicación de pinturas sobre bases pictóricas - recubrimientos ya de por sí deteriorados podrá comprometer su estabilidad a corto plazo provocando 

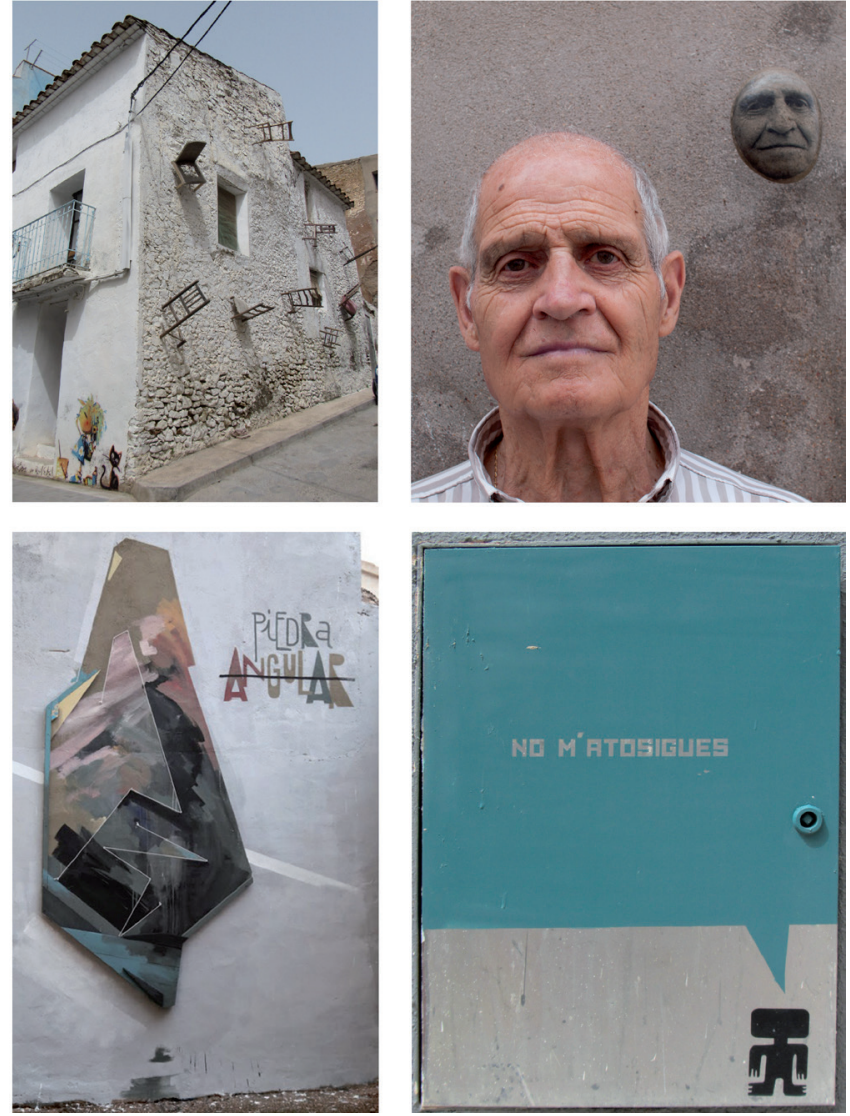

Figura5. Materiales en las obras de la Compañía de Mario, Hombre López, Xavier XTREM y Hombre López/Rafa Gascó. Fotos: Rafa Gascó (5b) y Mayte Pastor (5a, 5c y 5d).

su delaminación y pérdida, bien sea por fallos adhesivos y/o cohesivos e incluso por la migración sales en función de los distintos revocos (cal, cemento). Por tanto la aplicación o no de un tratamiento previo de las superficies condicionará su estabilidad futura.

Otra de las alteraciones que pueden dar pie a plantear la sustitución de un mural son sin duda los niveles de
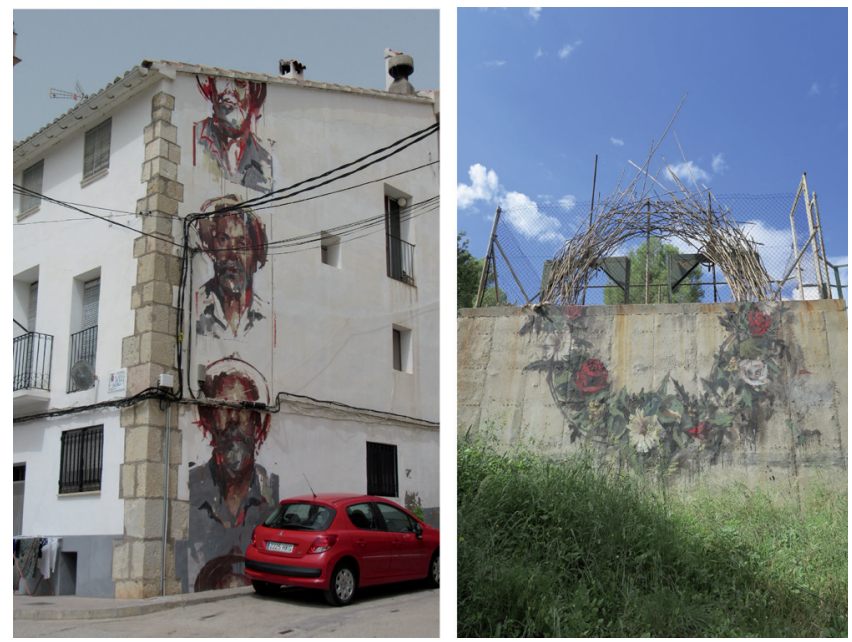

Figura 6. Materiales en la obra de Borondo: rostros y cables en mural y combinación de cañas y pintura (guirnalda). Fotos: Mayte Pastor y Rafa Gascó. decoloración por acción de la luz. En este sentido, las obras del M.I.A.U. combinan productos de mayor o menor resistencia, de los cuales pueden estimarse ciertos períodos de estabilidad.

En cuanto a la estabilidad cromática de los productos de Pinturas Colom $^{\circledR}$, tal y como especifica Francisco Vives director de la empresa ${ }^{9}$, la gama Mayen Color $^{\circledR}$, formulada con pigmentos inorgánicos y una elevada cantidad de resina, podrá mantenerse inalterada durante períodos superiores a cinco años, siempre y cuando los soportes y bases se encuentren en perfecto estado y sean las adecuadas. La formulación con pigmentos inorgánicos (tierras) en las líneas Tinmate ${ }^{\circledR}$ y Tintes Lys ${ }^{\circledR}$ proporcionará una alta durabilidad, mientras que la de los orgánicos será menor en exteriores (sus altas concentraciones pigmentarias son óptimas para interior). Dicha durabilidad se verá mermada si los tonos son rebajados con blanco al disminuir la concentración. Dependiendo de la orientación de la pintura, los colores 67-amarillo, 78-magenta y bermellón podrán presentar algún síntoma de decoloración. De forma orientativa de 1 a 2 años para los tres primeros y de 3 a 4 para el azul ultramar. En el caso de exigir el requisito de máxima durabilidad las pinturas pueden reformularse empleando pigmentos inorgánicos u orgánicos (calidad automoción), lo que incrementa su precio. Sin duda, una información de gran interés para la conservación, que puede trasladarse a los materiales empleados en reintegración cromática.

Las pinturas en aerosol para grafiti MTN $94^{\circledR}$ y Hardcore ${ }^{\circledR}$ presentan una durabilidad cromática en exterior de más de 10 años, si bien algunos tonos de rojo, amarillo, azul, verde, violeta y rosa tendrán una estabilidad menor, siendo baja la de los colores fluorescentes y la de los metalizados (Montana Colors 2016). Miguel Olias, departamento técnico de Montana Colors ${ }^{\circledR}$, señala que aunque en su formulación hay una prevalencia de los pigmentos inorgánicos para garantizar la estabilidad del color, se producirán cambios en las primeras semanas debido al amarilleo de la resina empleada manteniéndose la estabilidad a partir de dichas variaciones ${ }^{10}$. Al igual que Vives, insiste en la importancia del estado de conservación de los muros y recubrimientos, así como del tipo de condiciones ambientales (menor estabilidad en ambientes salinos). En la actualidad la empresa trabaja en la formulación de una línea de alta resistencia para obras de arte urbano planteadas para conservarse.

Aparte, cabrá contar con la reducida durabilidad de los materiales orgánicos (alimentos, vegetales...), así como la de las pinturas ejecutadas con tintas y acuarelas sensibles a la acción de la luz.

A lo anteriormente expuesto hay que añadir una cuestión habitual para la conservación del arte contemporáneo, que obliga a adaptar los criterios 
de conservación e intervención: la propia voluntad artística de que sean o no efímeras según su concepto, más allá de la propia resistencia de los materiales.

Pese a lo anterior, aquello que se planteó como efímero podría dejar de serlo en casos muy concretos. EI M.I.A.U., como proyecto social que es, en el que la máxima es precisamente la convivencia entre vecinos y artistas, abre una reflexión sobre la conservación futura de las obras. ¿Qué ocurrirá con aquellos murales que se han convertido en iconos de este festival?, ¿podrá la decisión popular pedir que una obra se conserve, máxime cuando se ha vivido de una forma intensa junto a los artistas que la crearon, perdiendo su carácter efímero? ¿O incluso, pueden los especialistas y críticos en historia del arte apoyar una petición así? Hay mucho que reflexionar y debatir, sin duda.

López, señala que efectivamente puede darse el caso, aunque depende en parte del artista, a quién se le da siempre la posibilidad de "restaurar" sus obras. Encontramos un claro ejemplo en el mural de Pol Marban, realizado a partir de una fotografía con gente del pueblo, mediante transparencias y aguadas, el cual presenta un importante nivel de decoloración, así como levantamientos y lagunas [Figura 7]. "Este año quería "restaurarse", pero el artista no ha podido venir, por lo que si el año que viene no se interviene, será sustituido por otro"11.

Sin entrar en debates sobre quién debe o no intervenir una obra, esta situación es sin duda muy interesante para la conservación del arte urbano, así como para el establecimiento de criterios específicos de intervención. Planteando desde el ámbito de la conservaciónrestauración la idoneidad de realizar un seguimiento anual del estado de conservación de las obras cuyos valores intrínsecos abren el camino hacia su posible conservación, junto a la aplicación de medidas de conservación preventiva, o a la realización de pequeñas intervenciones consensuadas con los artistas, haciendo

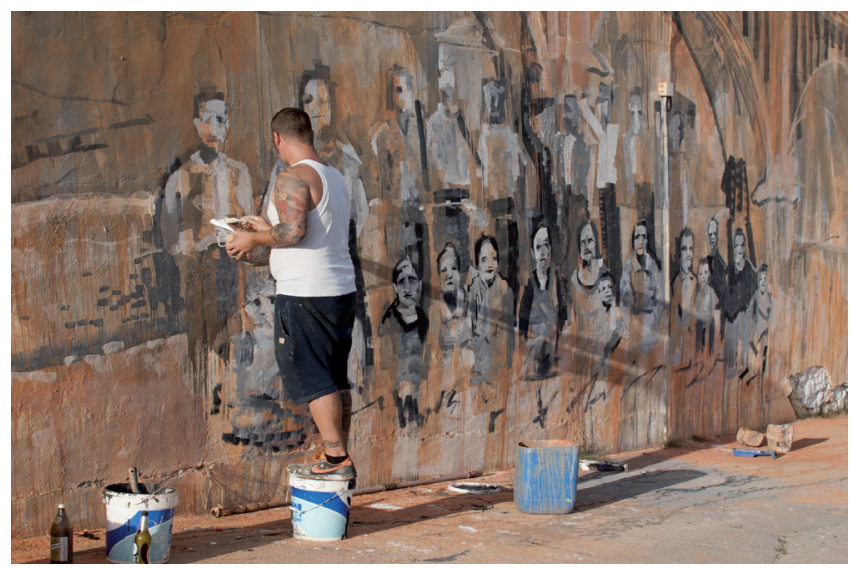

Figura 7. Pol Marban pintando mural. Foto: Rafa Gascó. posible la pervivencia de su imagen, materia y concepto. Nos referimos a la posibilidad que ofrecen algunos tratamientos tales como la aplicación de protectores frente a la acción de los rayos ultravioletas o a la realización de tratamientos puntales de fijación de estratos o incluso de reintegración cromática.

Para concluir, señalar que desde el M.I.A.U. se está realizando una labor de catalogación a través de la creación de un archivo fotográfico, que cuenta tanto con imágenes iniciales, de proceso, como finales, facilitando el estudio, investigación y consulta de las obras de este fantástico y excepcional museo al aire libre.

\section{Notas:}

[1] Colectivo G.U.A.U. (Gestores Universales de Arte Urbano): formado por Hombre López, Pincho, Xèlön, Justin Case, Ruina y Pol Marban, apoyan al festival como directores de artistas. Fuente: Javier López organizador del M.I.A.U, entrevista telefónica y vía WhatsApp agosto-septiembre 2016.

[2]- [4], [6]- [8] y [11] Fuente: entrevista a Javier López.

[5] Las señales de tráfico se realizan con acero y pintura epoxi y los contenedores tipo iglú con poliéster y fibra de vidrio y un recubrimiento exterior de alta resistencia fabricado por Gelcoats.

[9] Mayencolor blanco 205: bióxido de titanio (PW6) y negro humo (PBk7). Fuente: Francisco Vives Colom, responsable de dirección de Pinturas Colom, entrevista telefónica y vía email septiembre 2016.

[10] Fuente: Miguel Olias, departamento técnico de Montana Colors, entrevista telefónica 8/10/16.

\section{Bibliografía}

CHIANTORE, O., RAVA, A. (2005): Conservare I' arte contemporanea. Problemi, metodi, materiali, ricerche, Electa, Milán.

PUGLIESE, M. (2006): Tecnica mista. Materiali e procedimenti nell'arte del XX secolo, Bruno Mondadori, Milán.

SÁNCHEZ PONS, M., SHANK, W. Y FUSTER, L. (2015). Conservation Issues in Modern and Contemporary Murals. Cambridge Scholars Publishing, London.

VV.AA. (2007): Modern Paints Uncovered, GCl, Los Ángeles.

\section{Consultas Online:}

BOSCH, MANOLO. "MIAU hace de Fanzara la capital del arte urbano (II)". No me pierdo ni una. Web No me pierdo ni una. 
15/07/2015. <http://www.nomepierdoniuna.net/miauhace-de-fanzara-la-capital-del-arte-urbano-ii/>. [Consulta: 12/08/2016].

BOSCH, MANOLO. "Artistas y público dicen "sí" al MIAU Fanzara". No me pierdo ni una. Web No me pierdo ni una. 13/07/2016. < http://www.nomepierdoniuna.net/artistas-ypublico-dicen-si-al-miau-fanzara>. [Consulta: 06/09/2016].

GRAS CRUZ, IRENE. Web Irene Gras Cruz, historiadora y crítica del arte. NemO's en MIAU Fanzara. 28/03/2015. "Who is NemO's?" <https://irenegrascruz.com/2015/03/28/nemos-enmiau-fanzara/>. [Consulta: 30/08/2016].

I SUPPORTSTREETART. Web I Suport Street Art. @ 2016 ISSA Best viewed with a nice, cold beer. <http://www.isupportstreetart. com/>. [Consulta: 24/08/2016].

JO53-VALÈNCIA. "Fanzara 2015". 22/07/2015. Arte urbano, pintura mural y graffitis por Valencia. Blog. <http://larteurbano. blogspot.com.es/2015/07/fanzara-2015-1.html>. [Consulta: 30/08/2016].

M.I.A.U. Fanzara. @ MIAU Fanzara. Página web M.I.A.U. <http:// miau32.wixsite.com/miaufanzara>. [Consulta: 23/07/2016]; Facebook M.I.A.U. < https://www.facebook.com/pages/ MIAU-Fanzara/272752819594609?fref=ts>, <https://www. facebook.com/272752819594609/photos/a.273683079501 $583.1073741828 .272752819594609 / 485821451621077 / ?$ ty pe=3\&theater $>$. [Consulta: 12/08/2016] e Insharee M.I.A.U. Fanzara. <http://insharee.com/un/miaufanzara>. [Consulta: 12/08/2016].

MONTANA COLORS. Página web Montana Colors. Montana Colors (c) 2012. <http://www.montanacolors.com>, Fichas técnicas serie MTN 94 y Hardcore: <http://www. montanacolors.com/media/739_79_TDS_MTN\%2094_ SP.pdf>, <http://www.montanacolors.com/media/740_79_ MSDS-MTN\%2094-SPx1.pdf>, <http://www.montanacolors. com/media/715_79_TDS_Hardcore_SP.pdf>, < < $\quad<t$ :// www.montanacolors.com/media/714_79_MSDS-MTN\%20 HARDCORE-SPx1.pdf>, [Consulta: 12/07/2016 al 20/08/2016].

NITRACELULOSO. Nitrocelulosa Blog. nitraceluloso @gmail. com Ficha obras de Bibbito y Susie Hammer en Fanzara. <http://nitrocelulosa.tumblr.com/post/133411905553/pupobibbito-miau-fanzara-calle-santo >, <http://nitrocelulosa. tumblr.com/post/133475136582/susie-hammer-miaufanzara-traves\%C3\%ADa>. Consultas en general obras Fanzara. [Consulta: 09/08/2016].

PEZ, A. Blog personal. MIAU (Museo Inacabado de Arte Urbano) en Fanzara (Castellón). 30 septiembre 2014. <http://anapez. blogspot.com.es/>. [Consulta: 09/08/2016].

PINTURAS COLOM. Página web Pinturas Colom. OHijo de Guillermo Colom, S.A. <http://www.pinturascolom.com (c) Copyright - Pinturas Colom>, <http://www.pinturascolom. com/contacto/>, Ficha y ficha técnica serie Tinmate: $<$ http:// www.pinturascolom.com/tinmate-serie-a-b/> y <http:// www.pinturascolom.com/fichas-tecnicas/linea-deco/ pintura-mate-decorativa/FICHA-TECNICA-TINMATE-07-07-08. pdf $>$, Ficha y ficha técnica serie Mayen Color: <http://www. pinturascolom.com/mayencolor-liso/> y <http://www. pinturascolom.com/fichas-tecnicas/linea-deco/tratamientofachadas/FICHA-TECNICA-MAYENCOLOR-LISO-19-01-11. pdf> Ficha técnica serie Tintes Lys al agua: <http://www. pinturascolom.com/tintes-lys-al-agua/> y <http://www. pinturascolom.com/fichas-tecnicas/linea-deco/productosauxiliares/FICHA-TECNICA-TINTES-LYS-AL-AGUA-29-04-11. pdf $>$, Ficha técnica serie Acrilico color: <http://www. pinturascolom.com/acrilico-color/> y <http://www. pinturascolom.com/fichas-tecnicas/linea-deco/pinturamate-decorativa/FICHA-TECNICA-ACRILICO-COLOR-10-12-12. pdf>. [Consulta: 12/07/2016 al 20/08/2016].

THESAL, GRUPO MECATHESAL. @ Thesal 2013. “Contenedores de reciclaje". <http://www.thesal.es/contenedores_de_ reciclaje/contenedor_iglu/?active $=2 \&$ contenedor $=3>$. [Consulta: 27/08/2016].

\section{Agradecimientos:}

A los organizadores del M.I.A.U: Javier López y Rafa Gascó, por toda la ayuda prestada, por su infinita paciencia y amabilidad, gracias por vuestras correcciones y fotografías. A Enrique Vives, responsable de Pinturas Colom, por compartir su experiencia y resolver nuestras dudas a nivel técnico. A Miguel Olias, departamento técnico de Montana Colors por atender y despejar nuestras preguntas. A Joan Feliu, profesor de la UJ, por facilitarnos el contacto con el M.I.A.U. Y a Elena Gayo por su ayuda y apoyo.

Mostrar nuestro reconocimiento al proyecto social del M.I.A.U., a los organizadores, vecinos/as, artistas y colaboradores que hacen posible que el arte contemporáneo de calidad siga creciendo como un instrumento de cultura. 


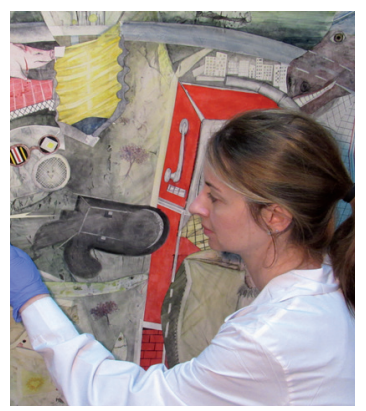

\author{
Ma Teresa Pastor Valls \\ Castellón de la Plana \\ maytepastorv@gmail.com
}

Doctora por la UPV en Conservación y Restauración de Patrimonio Pictórico (Premio extraordinario 2016),Título superior en Conservación y Restauración de Bienes Culturales en la Especialidad de Pintura (ESCRBCC) y Licenciada en Humanidades (UJ).

Ha colaborado en la redacción del Plan Nacional de Conservación de Patrimonio del Siglo XX (IPCE-MCU) como experto externo. Ha colaborado y trabaja como técnico superior en conservación restauración de arte contemporáneo desde 2007 para diversas instituciones y colecciones (Museu d’Art Contemporani Vicente Aguilera Cerni de Vilafamés, Instituto Valenciano de Conservación y Restauración IVC+R, Colección Martínez Guerricabeitia-UV, Fundación Anzo, etc.), actividad que combina en la actualidad con una beca de investigación posdoctoral Andrew Mellon Foundation dentro del Programa Catedral de Santiago, cuya finalidad es la de estudiar la estabilidad y viabilidad de los adhesivos y consolidantes a emplear en el tratamiento de las policromías del Pórtico de la Gloria. 